\title{
The value of art-oriented pedagogical approaches to the teaching of optics and photonics
}

\section{Stephen Pompea, Nancy Regens}

Stephen M. Pompea, Nancy L. Regens, "The value of art-oriented pedagogical approaches to the teaching of optics and photonics," Proc. SPIE 10452, 14th Conference on Education and Training in Optics and Photonics: ETOP 2017, 104526Q (16 August 2017); doi: 10.1117/12.2270021

SPIE Event: 14th Conference on Education and Training in Optics and Photonics, ETOP 2017, 2017, Hangzhou, China 


\title{
The value of art-oriented pedagogical approaches to the teaching of optics and photonics
}

\author{
Stephen M. Pompea a and Nancy L. Regens ${ }^{\mathrm{b}}$ \\ ${ }^{\mathrm{a}}$ The National Optical Astronomy Observatory, 950 N. Cherry Avenue, Tucson Arizona USA 85719 \\ ${ }^{\mathrm{b}}$ The University of Arizona (retired), Tucson, USA 85719
}

\begin{abstract}
Art-oriented pedagogical approaches have been successfully applied to optics and photonics education. We will describe how art-based programs that incorporate a Visual Thinking Strategies (VTS) approach can be used by optics and photonics educators. VTS encourages both a deep appreciation of the content of optics images and phenomena and a highly participatory approach to understanding them. This type of approach has been used by the authors in a variety of educational settings including teacher professional development workshops, museum and science center-based programs, after school programs and in two-week intensive summer academies for students. These approaches work well with multiple age groups including primary and secondary grade students, university students, and adults who may have little apparent connection to optics and photonics. This art-science hybrid approach can be used by university professors, optics/photonics professionals who do public programs, museum educators, and classroom science teachers.
\end{abstract}

Keywords: science education pedagogy, optics education, instructional materials development, visual thinking strategies

\section{INTRODUCTION}

People of all ages are attracted to light and color and are curious about them. How can we best engage them in the study of optics and photonics in school classrooms an in out of school environments? A traditional and often successful approach would be to create teaching materials such as classroom experiments or activities that explore key optics concepts. The next step is to train the educators leading the instruction so that they are able explain the key concepts and follow well-established pedagogical approaches. As the lessons or concepts they teach become more elaborate, additional subject matter or pedagogical training is required for the teacher or after-school educator to be successful. Although this approach can work well, it puts a heavy burden on the instructor, who may not have a strong science or engineering background. As teachers often are the gatekeepers to what is taught, it also might limit the frequency with which topics and concepts in optics and photonics are taught. If the teacher does not feel comfortable teaching about optics, the student may not have any exposure to it. Especially in the elementary school, there is a dearth of science instruction and the comfort level of the teachers with science is a key aspect of why science is not taught.

To increase the frequency and time spent on optics instruction at all grade levels, a different approach might be needed and is proposed here. This approach puts less responsibility on the teacher to understands the material quite well. It also promotes a different instructional model than the traditional teacher-student knowledge transmission model, where the teacher conveys their knowledge to the student using experiments and lectures. The model we are advocating focuses on the role of the teacher to be a facilitator of student science exploration, using an approach pioneered in museum-based art education.

\section{ART ORIENTED APPROACHES TO TEACHING OPTICS}

A previous paper ${ }^{1}$ described in detail how an art-oriented approach could be used in a program emphasizing the theme of "the colors of nature" to teach about optics. In this program, we held a series of two-week Summer Academies in 
Tucson, Arizona on the University of Arizona campus, and in Fairbanks, Alaska on the University of Alaska, Fairbanks campus. We combined art and science teaching techniques and encouraged experimentation and exploration. This approach gave students some science measurement tools, design challenges to pursue, access to young scientists as mentors, and plenty of time to explore and investigate natural phenomena related to color. The program emphasized scientific tools and used binoculars, eye loupes, regular light microscopes, electron microscopes, and visual and CCDbased spectrometers to explore and characterize color and how it could be created. The program also had components of chemistry experimentation that were related to color. ${ }^{2}$ The spirit of the program was also important. There was a focus on forming science identities in the participating girls-encouraging them to identify with the process of science. ${ }^{3}$ We asked the participants to be less self-critical and to be supportive of the creative works that they and their colleagues made. The subject matter explored how color is created and detected. It involved studying illumination sources and their colors, the reflectivity properties of materials, and the nature of detectors-human, insect, and crustacean eyes as well as electronic detectors. We found that this approach allowed science to be perceived as creative and fun.

In this paper we describe a different and even more accessible approach to integrating art and science. It utilizes strategies from art education and does not require laboratory equipment or even science subject matter expertise in the educator who leads the activities. We will describe an approach that captures the inquisitive nature of science investigation by encouraging students to ask and investigate their own questions after observing an optics phenomena or an image of one.

Since the approach focuses on the student, the teacher is not required to have a deep knowledge of optics. The teacher must be trained in how to lead the class using this suggested approach. The teacher plays the role of an educational facilitator rather than being a conduit for knowledge. This pedagogical approach can be taught and applied to many different areas of optics and photonics. A further advantage of this approach is that it can be used with young children and led by teachers with a minimal background in science or science teaching. When led by a teacher with a strong background in optics, it can be highly effective.

\section{THE VISUAL THINKING STRATEGY APPROACH}

In the art education world, there is a tension between approaches. Should art be explained or explored? At an art museum there is often a docent or museum educator who can lead visitors to one or more works of art and explain the context of the work, the technique and subject of the work of art, and some aspects of the artist and his or her approach and philosophy. This exposition can be done by a person standing next to and explaining the work of art. It can also be done through a written program handed out and then read by the visitor, by explanatory material at the exhibition (e.g. on the walls), or even through an audio device or cell phone giving a commentary. This well-established approach appears to be an effective way to present basic and more detailed authoritative information to the visitor.

However, a common side effect of this approach is that it puts the visitor into a passive mode of receiving information about the art piece rather than more fully engaging with the work of art. The other consequence of this expository approach is that the visitor often does not later remember the information presented, even if the explanation was interesting and well-organized. In an analogous situation, the college teaching lecture can be useful for conveying information, but there are many weaknesses to this approach when the educational outcomes are measured. ${ }^{4}$ Lectures are not particularly effective at stimulating interest in a topic or inspiring changes in attitude. ${ }^{5}$

An alternative approach is for visitors to observe art pieces and discuss their observations using a Visual Thinking Strategy (VTS) approach pioneered by Housen and Yenawine. ${ }^{6,7}$ This approach begins with participants silently studying the art object in a concentrated way, and then engaging in a discussion facilitated by the museum educator. By seeing the art piece deeply and directly (without a narrative by a docent about the piece), there is an enhanced opportunity for engagement and discussion, both of which have proven valuable. This approach has transformed the museum curricula, ${ }^{8}$ and has proven valuable in adult learning environments. ${ }^{9}$

The VTS approach and teaching method has several foundational characteristics:

- All of the participants can express their opinions on the artistic work. 
- The contributions will be met in a positive and affirmative way by the facilitator, who paraphrases the contribution and may point out those same specific aspects of the art work to reinforce the contribution.

- The facilitator shows interest in each comment or contribution, but is not judgmental.

- Each comment is acknowledged and considered by the group.

- The participants learn to value the different contributions and comments.

- The focus remains on the piece of art, with the instructor or facilitator pointing at the art to aid understanding of the comments.

- The participants learn that there are multiple meanings and opinions on a piece of art.

This approach engages the museum participant and allows them to personally interact with the painting, sculpture, drawing, or ceramic piece. The participant does not have to absorb detailed information about the art piece from a docent. Through this personal engagement, the art piece is remembered after the visit, since the visitor constructs their own knowledge of the piece and has their own personal and emotional relationship to it.

To achieve these results, the VTS facilitator (usually a docent or museum educator trained in using VTS) typically asks three questions:

- What's going on in this picture?

- What do you see that makes you say that?

- What else can you find?

These three questions, when posed after a deep examination of the piece, are powerful stimulants that help create a rich and personal discussion. This discussion leads to a deeper understanding of the art than by listening to a well-intentioned narrative about the piece. At the beginning stage of first experiencing a new work of art, explanations of the art work by a teacher may be appreciated, but much of the knowledge is not internalized or remembered. This technique empowers the visitor to become a keen and engaged observer.

\section{VISUAL THINKING STRATEGIES IN OPTICS AND PHOTONICS EDUCATION}

How can VTS be used in optics and photonics education? We've emphasized that a narrative or expository approach to education has its limitations. In optics/photonics education this narrative approach would be the instructor explaining and the student absorbing. While appearing to be a successful way of conveying knowledge, the engagement element is missing. For example, imagine a teacher deciding to try to explain how light works to young children. The vocabulary or the concepts may be too advanced for this age level, for example. An experiment or demonstration may be better but still requires the instructor to have a sensible understanding of what is being demonstrated, in order to answer questions. Most importantly, the instructor may never address the nature of light if they are feeling insecure in their understanding or have not idea how to approach this topic in an age-appropriate way.

Now imagine that the instructor demonstrates or shows an image of an optical phenomena-such as a laser beam bouncing off of a flat mirror, preferably with some dust to help make the beam visible. Or the teacher shows a picture of a rainbow. The instructor can show the phenomena and ask the standard VTS questions: What do you see? What makes you say that? What else do you see?

The students can observe closely and silently. Then they can start to discuss what they see. After the discussion, they can formulate their own questions about the phenomenon. Once they have formed some questions that are of interest to them, they can investigate. Their investigations might involve further experiments, talking to experts, or library research. The teacher can guide them in each of these directions. The instructor does not need to know the vocabulary. Indeed the vocabulary or labeling by the instructor may even be detrimental. Words like "plane mirror", "angle of incidence", and "normal to the surface" may only confuse the students or inject misconceptions. It may be better that they investigate reflection and bring what they have learned back to the group, rather than mapping their observations to the teacher's words or to a concept. That mapping and concept formation can come later. 
The process of using a VTS approach can combine observational skills with a high quality group discussion of what is observed. Both of these can lead to a deeper understanding. The discussion is not about getting to the right answer as quickly as possible and then being finished. It is about each student engaging and forming a personal view of the phenomena as well as forming personal questions of interest to them.

The VTS leader should also try to de-emphasize nomenclature, at least at first. Noticing that light seems to bend in a certain way as it goes through a lens is a powerful observation; simply saying that refraction is taking place may not yield any new insights, especially if the audience does not really understand what the term means or confuses it with another similar term. For example, calling a lens reflection in a photograph a "ghost" may further confuse the participants, especially younger participants who have a vivid imagination. It is more important for the leader to help create a supportive discussion of what aspects are being observed - the morphology, brightness, color, position, pattern, and under what circumstances the ghost image appears. The labeling might be appropriate or useful later on. The nomenclature or vocabulary should not be used too early, where it can short-circuit or confuse the observations or the discussion.

The value of a supportive atmosphere in which students can express and develop ideas should also not be underestimated. VTS is a process which can be applied in different situations. However, it always needs to be applied in an atmosphere where the individual observations are validated and respected. Again, the student observations are not aimed at a "right answer" or winning favor from the instructor. They should be genuine observations made by the students, and supported by the instructor. In the case of differing perspectives by the students, both points of view need to be articulated and validated, without any attempt to indicate which one is right. The initial emphasis is not on explaining the phenomena but on observing it.

The range of optical phenomena that can be used with VTS is nearly unlimited. Virtually every branch of optics and

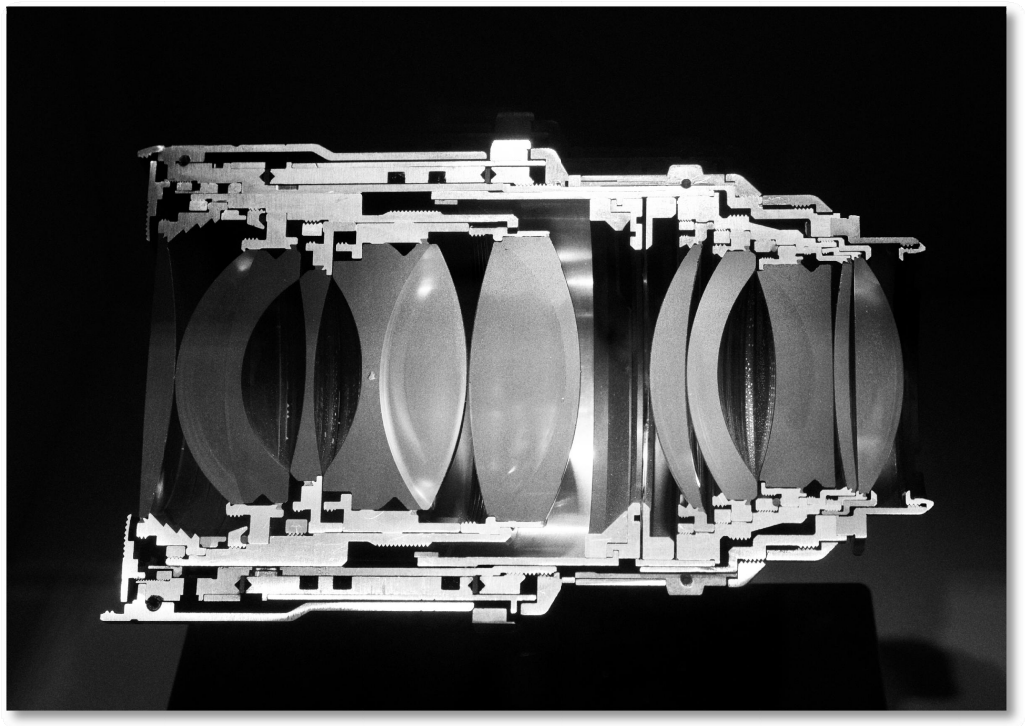
photonics may lend itself to a VTS teaching approach. Some aspects of optics that are accessible to primary or middle school students has been described in previous papers. ${ }^{10,11}$ In summary, any optical phenomena that can be visually examined may be appropriate for examining using a VTS approach. The easiest way for many instructors to use VTS is to use photographs of optical phenomena or optical systems. For example, one can examine the structure of a lens system that has been cut in half to expose the arrangement and shapes of the lenses. Students can notice various features of this system and can also examine such systems that have laser light tracing the refraction and reflection paths. VTS can also use a series of photos or even a movie.

Figure 1: Image of camera lens system suitable for examination and discussion using a VTS approach.

\section{WHAT ARE SOME TOPICS WHERE WE COULD APPY VTS?}

Virtually any topic in optics and photonics that can be observed, visually captured, or illustrated can be taught using the VTS approach. If the phenomena can be captured in a still image or movie, then that phenomena can be looked at closely and discussed. Again, note that VTS is not an attempt to discuss all aspects of a phenomena but rather an attempt to engage the learner in deep viewing and forming a personal reaction and engagement with what is being observed. The categories where images may be used for the VTS approach are wide ranging. 
Table 1: Topic areas that are amenable to a VTS approach. This is only a sample list.

\begin{tabular}{|l|l|l|l|}
\hline Wave Motion & Geometrical Optics & Electromagnetic Waves & Color \\
\hline Wavelength & Reflection from flat mirrors & Constructive interference & Scattering \\
\hline Frequency & Reflection from curved mirrors & Destructive interference & Glacial milk \\
\hline Amplitude & Specular reflection & Double slit & Colors in Glaciers \\
\hline Wave velocity & Diffuse reflection & Single slit & Fluorescence \\
\hline Superposition & Refraction & Diffraction grating & Birefringence \\
\hline & Refraction in water & Newton's rings & $\begin{array}{l}\text { Thin film } \\
\text { interference }\end{array}$ \\
\hline & Total internal reflection & Diffraction & Soap bubble colors \\
\hline & Light through a lens system & Dispersive effects & \\
\hline & Forming images & Light through fibers & \\
\hline & Focal points & Polarization & \\
\hline & Appearance of aberrations & & \\
\hline & Brewster's angle & & \\
\hline & Prisms & & \\
\hline
\end{tabular}

Some sample images which lend themselves to the VTS approach are given later. There are many other possibilities as well. Some that may be useful include photographs or the color variations of glacial ice, magnified views of a butterfly wing, minerals illuminated by normal room light and then ultraviolet light, auroral photographs, rainbows, and photographs of hummingbirds illustrating color changes due to structural color.

\section{THE THREE QUESTIONS OF THE VTS PROCESS}

In the VTS process, the students gather around a large photograph or project image. In some cases, it may be an experiment or optical demonstration. For the purposes of illustration, we will assume that a large photograph is being used. It is helpful if the group can all be gathered at the same distance, so that there is no "front row" and "back row." Once students examine the photo for a few silent minutes, the instructor can ask, in sequence, the three VTS questions.

\section{Question 1: What do you see?}

This question is directed at the group who are all equally able to see the image or demonstration. The instructor can call upon individuals to express their observation. The instructor should take some effort to hear from most members of the group and not let one person dominate the discussion. Sometimes it is best if each person states only one observation. The instructor can point to the area being discussed to make sure that the comment is understood. A second question can be asked at this same time of each observation:

\section{Question 2: What do you see that makes you say that?}

In this question is an opportunity to encourage the concrete link between the observation and the image. After each answer, the instructor can paraphrases the comment from that person and further encourage others who have not spoken yet. For further encouragement is needed, the instructors can ask the third question:

\section{Question 3: What else do you see?}

When most of the people have spoken or most of the features of the photo have been identified, the discussion can then center on how to investigate the points that have been raised. It is helpful to list the questions or points so all can see.

One consideration when leading this discussion is the use of labels or vocabulary words. The instructor should focus the discussion on what can be seen and described in the image and should try to deemphasize vocabulary and nomenclature. For example, if a beam of light is seen scattering off of dust particles, a student might say that they see a laser beam. This may be a red herring so the instructor should emphasize the description of what is seen rather than a label which may not be correct. Of course, if the instructor is well-versed in the topic then he or she can try to make sure that accurate labels are used and that inaccurate ones are not reinforced. It is better for the students to say that they see pink circular blobs of light than to put a label on it. For example, when students use VTS to examine astronomical images, every dark area 
might become a "black hole", even though the dark areas are dusty molecular clouds much larger than a black hole. It is far better to say that there is a jagged-shaped dark area. Assigning a correct or incorrect label to each morphological feature is not furthering an understanding.

From what is seen, the students can formulate questions about the relationships observed, the detailed morphological characteristics, or even the meaning or narrative of what is happening in the image. These questions can be recorded on paper or computer and distributed. After the questions have been investigated (which may take hours to weeks), the group can return to the image and discuss it further. A typical question for an investigation might be "I wonder why the red color is on the outside of the inner rainbow and on the inside of the outer rainbow."

\section{SAMPLE PHOTOGRAPHS FOR USE WITH VTS}

While nearly any photograph showing an optical phenomenon can be used with VTS, the instructor will learn with experience that some photographs lend themselves better to a VTS approach and make for a more productive group discussion. It is important that all of the group members be able to examine the photograph (up close if necessary) for an extended period of time. It is certainly useful if the image is projected large enough so that all of the group can see it easily and pick out details. A large print is also conducive to this process.
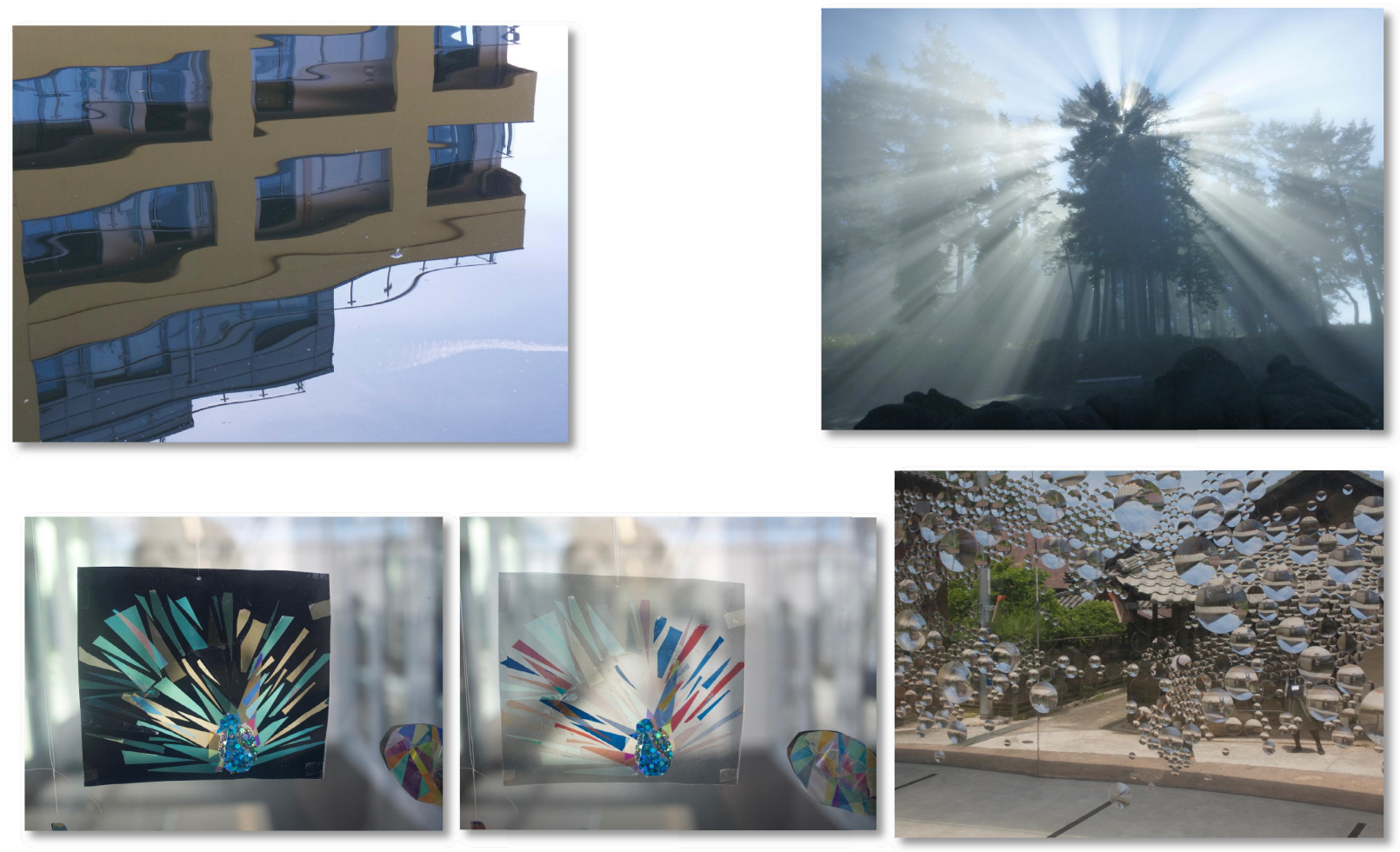

Figure 2: Examples of photos used in a Visual Thinking Strategy approach. Clockwise from upper left: Reflection of building and aircraft contrail in a canal (Leiden, the Netherlands). The Sun, as viewed through trees from just off shore (San Juan Islands, Washington state). An art display with multiple lenses embedded in a transparent wall (Japan). Photos of two art piece made using cellophane layers, a polarizing layer, and photographed through a polarizing filter. The second photo was taken with the polarizing filter in a different orientation.

\section{WHO CAN USE THIS APPROACH?}

The VTS approach is quite versatile and can be used by many different kinds of educators and audiences. 
Preschool: VTS has been used successfully in examining art with children ages 3-6 and there is no reason to believe it cannot be done to study optics with children at this highly inquisitive age. It is valuable to ask children in this age range to explain their reasoning (VTS Question 2: "What makes you say that?"), as this builds their reflection and evaluation skills into the discussion. Reflective thought becomes a regular intertwined skill in the discussion and not an afterthought or reflection upon the process. ${ }^{12}$

Elementary or Primary School (Years 1-5 of School in the United States): The VTS approach can be used by the teacher to examine any number of optical phenomena, especially when they are presented in an image. For example, a photo of a rainbow (or double rainbow) can be examined using the VTS approach. The educator does not have to be conversant with the science of rainbows or even the basic attributes of rainbows. The attributes of a rainbow can be observed by the students and the science of how they are formed can then be researched by them. While very few elementary teachers would feel comfortable teaching the science of rainbows, many would be comfortable introducing rainbows through VTS. The students can then find appropriate science books in the library that explain rainbows and perhaps have demonstrations that they can do to illustrate aspects of how a rainbow forms.

Middle School (Years 6-8 of School in the United States): In the United States, many middle school science teachers do not have specialized training in science. In many states, elementary school teachers can teach in middle schools as well. A VTS approach can be used by these science teachers who lack specialized training in the physical sciences. Thus a science teacher with a biology background can use VTS to address physical science topics such as optics.

High School (Years 9-12 of School in the United States): Physical science teachers can use VTS to encourage deeper explorations of physical phenomena. VTS can be used with photographs, movies, and with demonstrations. Physics and chemistry teachers can use VTS very easily since they have access to many good demonstrations and images.

University Level: VTS can be used by faculty to engage students and to encourage deeper observations. VTS can also be used by university students doing optics outreach programs in the schools.

General Public: VTS has been used most often with the general public in art museums. It can be used equally well in introducing optics and photonics to the public.

What level of training is needed? Although training is invaluable, we suggest that optics educators try this approach and seek further training as they recognize the need. The VTS approach is well described in many articles and at least one book. ${ }^{13}$ Special courses on using VTS are offered at museums throughout the United States by the VTS organization (http://vtshome.org/).

\section{ADVANTAGES OF THIS APPROACH}

This VTS approach has several advantages. First, there is very little equipment needed. An interesting image that everyone can see can form the basis of a lesson. Second, the amount of subject matter training needed by the instructor can be minimized. The instructor must be trained on the technique but does not have to be trained on the subject matter in detail. This makes the lesson much more accessible to the teacher and takes pressure off of them. The teacher does not need to have large or comprehensive knowledge of the subject matter in order to succeed. Of course, an instructor wellschooled in optics can be extremely effective in using this approach. Third, the teacher can use the lesson to motivate students to investigate further. As in the process of doing science, students ask questions and try to find out answers. This is in contrast to an approach where the teacher has the right answer and the students must find it, memorize it, and reproduce it on a test. With VTS, the evaluation conducted by the teacher can be more authentic by focusing on the process that students use to formulate their questions and find answers to them.

The program is also highly adaptable to different grade or knowledge levels. Almost any image has layers of knowledge that can appeal to different knowledge levels. The program can successfully engage students by letting them pursue answers to questions that are of personal interest and that were formulated by them. Finally, an additional advantage is 
that the program can work equally well in a formal, classroom environment and in a free-choice museum or out of school environment.

Although using this approach may be slightly uncomfortable at first, the instructor should recognize that VTS has been used in diverse fields, such as medical education. ${ }^{14}$ The key to using VTS is to know the educational needs of your audience and what your educational goals are in relation to that audience. For younger students or even for adults with little experience in observing optical phenomena, the goal might be to increase interest and to have the audience notice optical phenomena in the world around them. For a more experienced audience, the goal might be to create a narrative about how light moves or works, such as how light moves through a series of lenses in a camera. For a very experienced or expert group it might be to begin a high-level discussion about a more complex phenomenon, such as the morphology of an auroral display.

\section{AESTHETIC DEVELOPMENT FROM THIS APPROACH?}

Can a deep appreciation of optics phenomena be achieved through VTS? We think so, based on the experience of art educators. Since works of art are often visited many times over a period of years, there can be an evolving relationship with the art and its meaning to the viewer. This further element of using a Visual Thinking Strategy approach is based on Housen's stages of aesthetic development, which describes the different stages in understanding a work of art. ${ }^{15}$ The five stage that she describes are summarized below and have analogues in viewing optical phenomena.

Stage 1 (Accountive) In this stage the viewers use their memories and associations to create a narrative based on their concrete observations of a work of art. The viewer's emotions and judgments play a role and color their comments.

Stage 2 (Constructive) In this stage the viewer builds a logical framework for looking at art using their own knowledge and perception and their own social and moral values. If the art work is incongruent with the viewer's values of skill or technique, for example, the viewer may judge the work harshly or diminish its value. Realism is often valued and the viewer may distance himself or herself from works judged to be deficient, especially if they are unaware of their feelings and emotional responses to a work.

Stage 3 (Classifying) The viewers in this stage often adopt the perspective of an art historian and can be critical in their analysis of a work. An effort is made to place the time, style, or school. The work is placed in the viewer's context and decoded using these constructs in an effort to create understanding of the message and meaning of the work from an understanding of the category or niche that the work is categorized in.

Stage 4 (Interpretive) The viewers in this stage have a more personal encounter with the work as they explore it in detail, over time. The subtleties of the work are appreciated and the viewer's critical skills are used again, but this time as an extension of the feelings and intuitions about the work. Each new opportunity to experience the work can lead to new insights, interpretations, or comparisons and the viewer can notice the change process in themselves.

Stage 5 (Re-Creative) The viewers in this category now can approach the work from new directions, with their long history with art and reflecting on particular works of art. They are willing to be surprised, even though they know many intimate details about the work. They have a long-lasting and intimate friendship with a work of art and can combine personal contemplation of it with other viewpoints that reflect more universal themes or concerns. Memory plays a key role in how they react to the painting and how they place the painting in a broader landscape, or place the work in its larger ecological framework.

VTS can be used in the same way to appreciate the aesthetics of optical phenomena and to form a long-term relationship with it. We are encouraging in students something similar to what the Nobel-prize winning geneticist Barbara McClintock called in biology research "a feeling for the organism."16 Repeated viewing of optical phenomenon may lead to an enhanced appreciation and to a deeper understanding. 


\section{CONCLUSION}

In an attempt to encourage more optics and photonics education in all school grade levels and to make science education more accessible, we have explored the use of the Visual Thinking Strategies (VTS) approach in science education. This approach, though simple in its outline, represents a powerful approach that can engage students and allow them to explore optical phenomena. The approach centers on a deep contemplation of optical phenomena coupled with a supportive, non-judgmental discussion of the observations. These two stages lead to further student-centered exploration. The approach emphasizes appreciation and observation, rather than explanation or right answers. As such, this approach models the scientific exploration process much better than an expository approach centered on the instructor.

\section{Acknowledgements}

Project STEAM: Integrating Art with Science to Build Science Identities among Girls" is supported by the National Science Foundation under AISL Grant Number DRL-1224020 from the National Science Foundation. Any opinions, findings, and conclusions or recommendations Expressed in this material are those of the author and do not necessarily reflect the views of the National Science Foundation. The National Optical Astronomy Observatory is operated by the Association of Universities for Research in Astronomy (AURA), Inc. under a cooperative agreement with the National Science Foundation.

\section{REFERENCES}

[1] Pompea, S.M. and Carsten-Conner, L.D., "Teaching Optics Concepts through an Approach that Emphasizes the Colors of Nature, Education and Training in Optics and Photonics, Optical Society of America, OUT01 (2015)

[2] Teal Sullivan, P., Carsten Conner, L.D., Guthrie, M., Pompea, S., Tsurusaki, B. K., and Tzou, C., "Colorful Chemistry,” Science and Children, National Science Teachers Association, April-May, $34-40$ (2017)

[3] Tzou, C., Conner, L., Guthrie, M., \& Pompea, S., "Colors of Nature: connecting science and arts education to promote STEM-related identity work in middle school girls ” In Polman, J. L., Kyza, E., O'Neill, D. K., Tabak, I., Penuel, W. R., Jurow, A. S., O'Connor, K., Lee, T., and D'Amico, L. (Eds.). Proceedings of the International Conference of the Learning Sciences (ICLS) 2014: Learning and becoming in practice 3:1555-1556 (2014).

[4] Kozma, R.B., Belle, L.W., and Williams, G.W., [Instructional techniques in higher education] Englewood Cliffs, NJ: Educational Technology Publications (1978).

[5] Bligh, D.A., [What's the Use of Lectures?] Intellect books (1998).

[6] Housen, A. and Yenawine, P., "Visual thinking strategies: Understanding the basics" VUE: Visual Understanding in Education (2001)

[7] Yenawine, P., [Visual Thinking Strategies: Using Art to Deepen Learning across School Disciplines] Harvard Education Press, Cambridge, MA 02138 (2013).

[8] Burchenal, M. and Grohe, M., “Thinking through art: Transforming museum curriculum”, Journal of Museum Education, 32(2), pp.111-122 (2007).

[9] Landorf, H., "What's going on in this picture? Visual thinking strategies and adult learning ", New Horizons in Adult Education and Human Resource Development, 20(4), pp.28-32 (2006).

[10] Pompea, S.M. and Nofziger, M.J., "Resources on optics in middle school education ” Proc. SPIE, Vol. 225 (1995).

[11] Pompea, S.M. and Stepp, L.M., “Great ideas for teaching optics " SPIE International Symposium on Optical Science, Engineering, and Instrumentation, pp. 168-172, (1995).

[12] O'Leary, S., "What Do You See That Makes You Say That?: The Role of Asking Young Children to Provide Evidence for their Observations in Visual Thinking

Strategies Discussions," Master's Paper, Tufts University, downloaded from http://vtshome.org/research/ (2010).

[13] Yenawine, P., [Visual Thinking Strategies: Using Art to Deepen Learning across School Disciplines], Harvard Education Press, Cambridge, MA 02138. (2013).

[14] Reilly, J.M., Ring, J. and Duke, L., "Visual thinking strategies: a new role for art in medical education ” Fam. Med, 37(4), pp.250-252 (2005).

[15] Housen, A., "What is beyond, or before, the lecture tour? A study of aesthetic modes of understanding " Art Education, 33(1), pp.16-18 (1980).

[16] Keller, E.F., [A feeling for the organism, 10th anniversary edition: the life and work of Barbara McClintock], Macmillan (1984) 